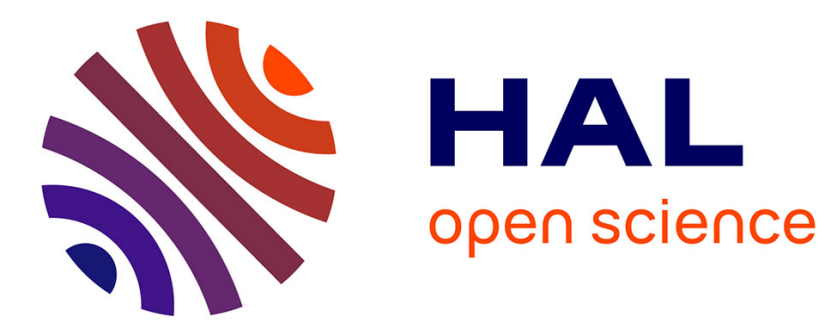

\title{
How pathogens affect root structure
}

\author{
Michael Quentin, Tarek Hewezi, Isabelle Damiani, Pierre Abad, Thomas \\ Baum, Bruno Favery
}

\section{To cite this version:}

Michael Quentin, Tarek Hewezi, Isabelle Damiani, Pierre Abad, Thomas Baum, et al.. How pathogens affect root structure. Root genomics and soil interactions, Wiley-Blackwell, 5p., 2012, 978-0-470-960431. 10.1002/9781118447093.ch10 . hal-02804727

\section{HAL Id: hal-02804727 https://hal.inrae.fr/hal-02804727}

Submitted on 5 Jun 2020

HAL is a multi-disciplinary open access archive for the deposit and dissemination of scientific research documents, whether they are published or not. The documents may come from teaching and research institutions in France or abroad, or from public or private research centers.
L'archive ouverte pluridisciplinaire HAL, est destinée au dépôt et à la diffusion de documents scientifiques de niveau recherche, publiés ou non, émanant des établissements d'enseignement et de recherche français ou étrangers, des laboratoires publics ou privés. 


\title{
10 How Pathogens Affect Root Structure
}

\author{
Michaël Quentin, Tarek Hewezi, Isabelle Damiani, Pierre Abad, Thomas Baum, \\ and Bruno Favery
}

\section{Introduction}

Several groups of soil microorganisms cause diseases to the roots. These "soilborne" plant pathogens are particularly challenging since they often survive in soil for many years and each crop may be susceptible to several species. They belong to various systematic groups. Major groups are oomycetes, fungi, bacteria, protists, and nematodes. Few soilborne viruses affect vegetable crops. The impact of these pathogens on the growth of plants can be massive. They may lead to the complete destruction of the roots and subsequently of the plants. Soilborne pathogens cause three major types of disease: (i) damping off caused by oomycetes such as Phytophthora, Pythium, and by fungi such as Rhizoctonia species, when seeds or seedlings are killed before or after germination; (ii) vascular wilt when the pathogens (e.g., Fusarium or soilborne Ralstonia bacteria) penetrate the roots and infect the xylem vessels, which become plugged; and (iii) root and crown rots caused by species of Phytophthora, Rhizoctonia, Fusarium, Gaeumannomyces, and Sclerotinia (Katan 1996). In addition, plant-parasitic nematodes and biotrophic protists (Plasmodiophora) are obligate parasites able to induce dramatic morphological and physiological changes in host roots. Infected roots undergo a developmental switch that results in the formation of aberrant root structures (clubs or root-knots) (Figure 10.1). The most intriguing pathogens in this group are sedentary endoparasitic nematodes. Two of the most economically damaging groups are the rootknot nematodes (RKN, Meloidogyne spp.) and the cyst nematodes $(\mathrm{CN})$. CN are mainly represented by the two genera Globodera and Heterodera. These microscopic roundworms invade the roots and engage in sophisticated interactions with their host plants inducing the formation of permanent feeding sites. These nematodes only feed after they have reached their destination in the host roots and have become sedentary by selecting a feeding site. These feeding sites consist of cells within the vascular cylinder, which become completely reorganized, hypertrophied, and metabolically highly active and serve as food sources throughout the nematode life cycle. It remains unclear how these pathogens cause such root alterations, but increasing evidence showed that nematode parasitism proteins, secreted from the esophageal gland cells through a hollow protrusive stylet, have direct effects on plant metabolic and developmental pathways to reprogram cells for feeding cell ontogenesis (Davis et al. 2008; Bird et al. 2009; Gheysen and Mitchum 2011).

This chapter reviews biology and molecular insights into mechanisms and plant developmental pathways manipulated by RKN, CN, and Plasmodiophora brassicae, elucidated in the last years 

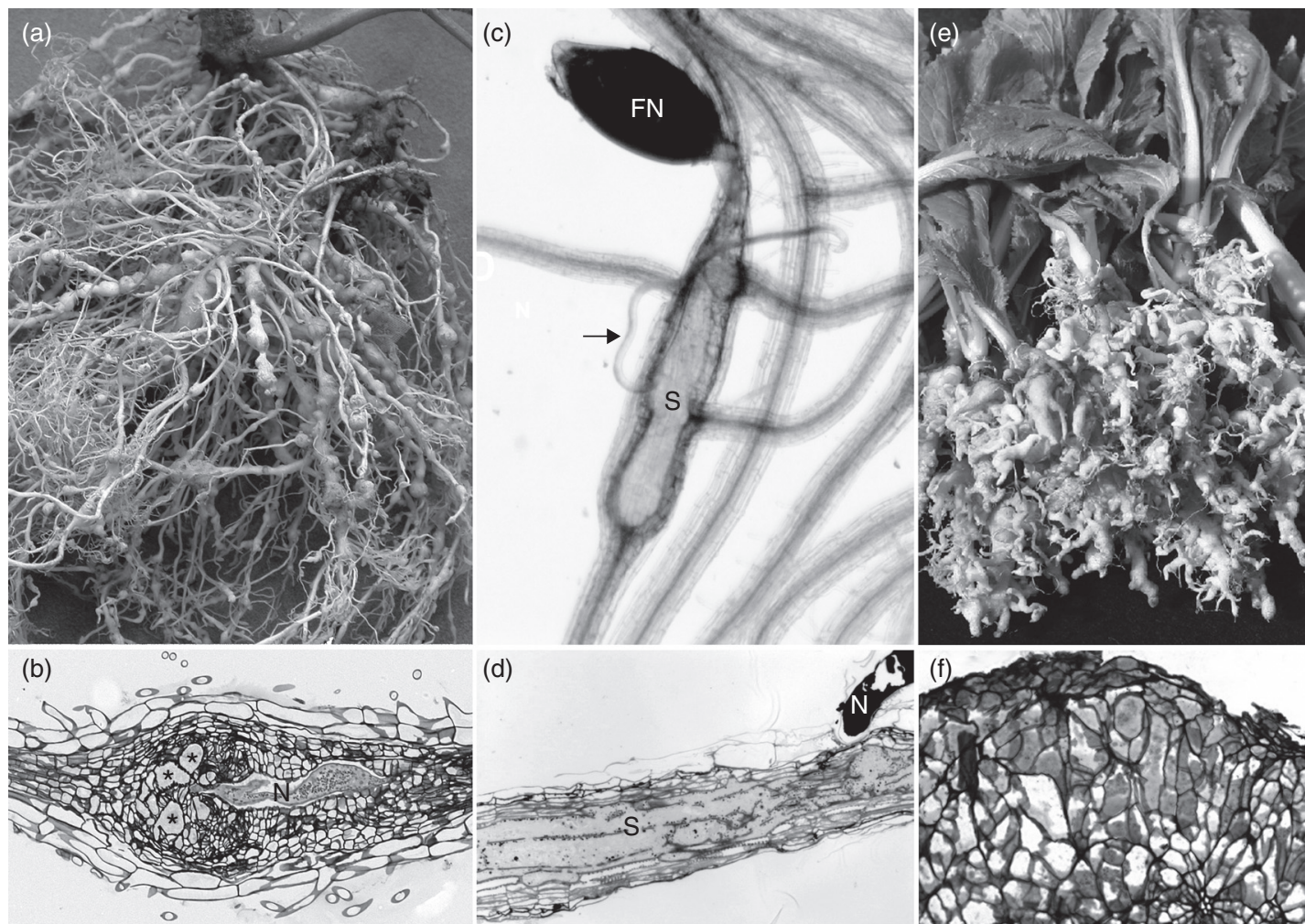

(d)

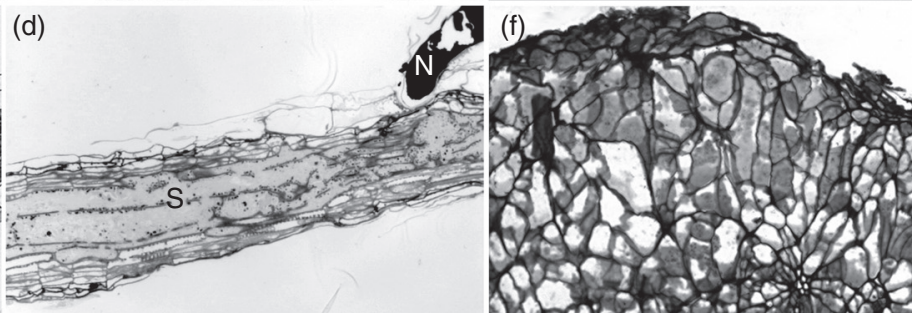

Figure 10.1 Root responses to RKN, CN, and Plasmodiophora brassicae infection. (a) Galls on tomato roots infected by $M$. incognita. (b) Multinucleate and hypertrophied giant-cells induced by $M$. incognita in Arabidopsis roots. Sections through a gall 15 days post infection. Asterisks, giant cells; N, nematode. (c) Feeding site induced by the sugar beet cyst nematode $H$. schachtii in Arabidopsis roots. Shown is a sedentary adult female nematode (FN) feeding from the syncytium (S) and a nonfeeding male (indicated by arrow). (d) Section through the head of the nematode (N) and the syncytium (S) showing partial cell wall degradation and cell-to-cell fusions. (e) Illustration of severe clubroot symptoms on young Brassica rapa roots. (f) Section through Arabidopsis Col-0 root 21 days postinoculation with $P$. brassicae. Note cell proliferation and enlargement resulting in a disorganization of tissue structure. Bars $=100 \mu \mathrm{m}$.

by transcriptome profiling and functional analysis. Recent characterizations of nematode parasitism protein plant targets are also presented.

\section{Root Infection and Feeding Cell Ontogenesis}

The RKN are able to form root galls (Figure 10.1a) resulting from cell hypertrophy and hyperplasia in nearly all flowering plants (Abad and Williamson 2010). The wide host range is associated with a worldwide distribution in all temperate and tropical areas, making them among the most damaging crop pests (Trudgill and Blok 2001). These nematodes infect roots as microscopic vermiform second-stage juveniles (J2) hatched in the soil. J2s are attracted to the host root, penetrate the root close to the root apex, and migrate between cells to reach the root apex and then enter into the plant vascular cylinder. To further develop and molt into a pear-shaped female that will release 
hundreds of eggs on the root surface in a protective gelatinous matrix, J2 need to successfully establish and maintain specialized feeding sites within the root. RKN induce the redifferentiation of five to seven selected pro-vascular root cells into elaborate feeding structures called "giantcells" (GC; Figure 10.1b) from which they withdraw water and nutrients, allowing their sedentary biotrophic lifestyle (Caillaud et al. 2008b; Abad et al. 2009). These cells undergo successive nuclear division (karyokinesis) without complete cytokinesis, leading to the formation of multinucleate cells that can contain up to 100 nuclei (Jones and Payne 1978; Caillaud et al. 2008c). Meanwhile, GC expands tremendously and can reach 400 times the size of a normal parenchyma root cell. From 3 days postinfection (dpi), cell walls (CWs) thicken extensively. CW ingrowths typical of transfer cells develop to increase cell membrane surface and facilitate solute flow from vascular cells to GC, thus allowing nutrient acquisition by the parasitic nematode (Jones and Dropkin 1976). Once mature, the highly metabolically active multinucleate and hypertrophied GC present typical features such as dense granular cytoplasm filled with numerous organelles and small vacuoles, and high osmotic potential (Jones and Payne 1978; Jones 1981). Concomitant to feeding cell ontogenesis, a proliferation and expansion of cells surrounding the GC is observed, leading to the formation of a gall, the visible disease symptom (Figure 10.1a).

The $\mathrm{CN}$ are also very specialized and successful plant-parasitic pests in agriculture. However, their host range is usually very narrow. Root modifications are also a hallmark of infections by CN (Figure 10.1c) (Sobczak and Golinowski 2011). Macroscopically, the effects of CN attack appear less severe than those of the RKN or clubroot disease at the first glance. However, roots frequently are stunted and, more interestingly, show increased branching with lateral roots. The latter is most dramatically illustrated by the root "beard" of sugar beets infected by the sugar beet CN Heterodera schachtii. However, the whole extend of root changes becomes evident when observing infected roots microscopically or molecularly. At the heart of the $\mathrm{CN}$ infection lays the feeding site. Preparasitic J2s penetrate the root system of their hosts and migrate intracellularly through root cortical cells until they reach the differentiating vascular cylinder where they induce the formation of permanent feeding sites, so-called syncytia. In contrast to GC, and as the name implies, syncytia are formed by the fusion of independent cells. CN initiate contact with the initial feeding cell by inserting its stylet through the $\mathrm{CW}$ and invaginate the plasmalemma. Following this nematode-plant cell contact, dramatic cellular changes are set in motion at whose end the formation of the syncytium as a novel plant root organ is accomplished. In the course of these changes, the initial feeding cell loses its central vacuole and replaces it with cytoplasm densely filled with organelles. Early on in the interaction, the cell's nucleus undergoes changes by reentering a shunted version of the cell cycle. While chromosome complements are replicated, the nucleus does not divide but sets out on a course of repeated endoreduplication cycles. Most impressively, these changes are replicated in neighboring cells, which ultimately fuse with each other and the initial feeding cell through CW dissolution to form the continuous cytoplasm of fused and modified root cells that make up the syncytium (Figure 10.1d). Up to several hundred cells are modified and incorporated into this structure, and together with modified cells surrounding the syncytium proper, these modifications literally result in the production of a novel plant organ (Grundler et al. 1998, Sobczak and Golinowski 2011).

Impressive impact on root structure is also caused by $P$. brassicae (Figure 10.1e). Its disease symptom is called clubroot as distortions give the shape of a club or spindle to the root. These gall-like structures represent strong sinks for assimilates from which the pathogens are completely dependent for feeding. Clubroot is a common disease of cruciferous plants, although $P$. brassicae can also infect noncruciferous plants in Gramineae, Rosaceae, Papaveraceae, Polygonaceae, Resedaceae, and Leguminosae (Ludwig-Müller and Schuller 2008). P. brassicae is an obligate parasite within 
the class Phytomyxea of the protist subgroup Rhizaria and is characterized by a complex life cycle (Kageyama and Asano 2009). Motile primary zoospores released from germinated resting spores, the survival stage in the soil, reach the root hairs. They penetrate the $\mathrm{CW}$ through a specialized device called "Stachel" and "Rohr" that injects their cytoplasm into the host during the primary phase of the infection, which is restricted to root hairs (Ludwig-Müller 2009). The parasite nuclei divide to produce a multinucleate primary plasmodium, which then cleaves to release the secondary zoospores into the soil. These zoospores enter a secondary infection cycle of the hypocotyls and the root cortex before migrating in direction of the central stele. Again, multinucleate plasmodia are formed. These phenomena are accompanied by plant cell nuclear divisions followed by cell elongation, leading to abnormal tissue proliferation forming the gall symptom (Figure 10.1f). When resting spores develop, the host tissue undergoes senescence and the resting spores are released into the soil.

\section{Genome-Wide Analysis of the Plant Response to Infection}

To unravel the plant molecular responses involved in the RKN or $\mathrm{CN}$ infection process, different molecular approaches have been undertaken, ranging from cDNA subtraction or differential display, promoter-reporter gene constructs, reverse-transcription polymerase chain reaction, mRNA in situ hybridization, to promoter-trap strategies (Gheysen and Fenoll 2002; Caillaud et al. 2008b; Abad et al. 2009).

Comprehension of the host gene expression patterns benefited from the development of plant microarrays allowing acquisition of large-scaled transcriptomic data. These studies were conducted during compatible interactions between Meloidogyne spp. and susceptible Arabidopsis thaliana (Hammes et al. 2005; Jammes et al. 2005; Fuller et al. 2007; Barcala et al. 2010), tomato (Solanum lycopersicum) (Bar-Or et al. 2005; Schaff et al. 2007; Bhattarai et al. 2008; Fosu-Nyarko et al. 2009; Portillo et al. 2009), cowpea (Vigna unguiculata) (Das et al. 2010), and soybean (Glycine max) (Ibrahim et al. 2011). Additional data were obtained during incompatible interaction between the RKN and resistant tomato (Schaff et al. 2007; Bhattarai et al. 2008) or cowpea (Das et al. 2010). Some of these genome-wide scaled studies were done using whole infected roots (Hammes et al. 2005; Ibrahim et al. 2011). Further manual gall dissection allowed sample enrichment in GC transcripts (Bar-Or et al. 2005; Jammes et al. 2005; Fuller et al. 2007; Das et al. 2010). From these experiments, it remained, however, difficult to identify genes specifically expressed within the feeding cells. Galls are indeed multicellular structures composed of different tissues and cell types. A first attempt on cytoplasmic content microaspiration revealed GC-specific gene regulation (Wang et al. 2003). Ongoing technical advances in laser-assisted microdissection makes it a powerful tool to explore the complexity of plant-microbe interactions (Ramsay et al. 2006), and it has been applied to decipher mechanisms involved in GC ontogenesis more accurately (Ramsay et al. 2004; FosuNyarko et al. 2009; Portillo et al. 2009; Barcala et al. 2010; Ithal and Mitchum 2011). These studies confirmed the molecular distinctiveness of the $\mathrm{GC}$ within the gall. A remarkable finding is that nascent GC are characterized by a main gene repression and that the majority of the differentially regulated genes have not, until now, been attributed a function (Barcala et al. 2010). To date, little attention has been given to GC-surrounding cells, and we do not know if they could contribute to the signaling leading to GC ontogenesis or to nutrients flow, but regulation of some genes, such as the Medicago truncatula ENOD40, has been reported to be restricted to these surrounding cells. It is obvious that laser-assisted microdissection approaches could also provide information on these particular tissue specificities and functions. 
Similar approaches have been applied, allowing a global view on changes in gene expression in $\mathrm{CN}$ feeding sites. Experiments were done on whole roots or dissected root segments of Arabidopsis plants infected with Heterodera schachtii (Puthoff et al. 2003) and soybean infected with Heterodera glycines (Alkharouf et al. 2006; Ithal et al. 2007a; Klink et al. 2007b; Puthoff et al. 2007). Laser capture microdissection has also been successfully applied to study the transcriptome of syncytia induced in soybean roots by H. glycines (Alkharouf et al. 2004; Ithal et al. 2007b; Klink et al. 2007a). A recent paper described the transcriptome of microaspirated syncytia induced by H. schachtii on Arabidopsis roots (Szakasits et al. 2009). Furthermore, extensive microarray studies were conducted to analyze the soybean transcriptome during incompatible interactions (Klink et al. 2007b, 2009, 2010; Kandoth et al. 2011). Altogether, available data highlight that the development of the nematode-induced feeding structures is associated with massive changes in the expression of genes linked to fundamental aspects of plant development such as cell cycle regulation, cytoskeleton organization, hormone response, CW remodeling, transport or regulation of gene transcription, and plant defense (Gheysen and Fenoll 2002; Caillaud et al. 2008b; Gheysen and Mitchum 2009).

Genomic studies on plant responses to P. brassicae remain scarce. To study pathogen-induced changes in host physiology during club formation, proteomic approaches have been used (Devos et al. 2006; Cao et al. 2008), and, to date, only one microarray analysis, using the Arabidopsis fullgenome Affymetrix chip, has been reported (Siemens et al. 2006). Data show differential expression of genes related to cell cycle, sugar metabolism, and defense. A major trend emerging from these studies is the transcriptional regulation of genes involved in the plant growth regulator homeostasis, particularly auxin and cytokinin (Ludwig-Müller et al. 2009).

\section{The Plant Cytoskeleton Is Targeted by Root Pathogens}

The plant cytoskeleton is a highly dynamic and flexible intracellular scaffold composed mainly of microtubules (MTs) and actin filaments. It plays a central role in intracellular transport, cell division, cell differentiation, and morphogenesis. Its dynamics are controlled by diverse actinbinding proteins (ABPs), microtubule-associated proteins (MAPs), and their regulating kinases and phosphatases. The manipulation of the plant cytoskeleton is a main step in nematode feeding site formation and is necessary for successful completion of the nematode life cycle. Chemical blocking (stabilization) or depolymerization of the actin or MT cytoskeleton influences nematode feeding site formation and consequently nematode development (de Almeida Engler et al. 2004; de Almeida Engler and Favery 2011). During compatible plant-nematode interactions, the actin network suffers structural changes (de Almeida Engler et al. 2004; de Almeida Engler et al. 2010; de Almeida Engler and Favery 2011), and the MT network is also rearranged for nematode feeding site ontogenesis (de Almeida Engler et al. 2004; Caillaud et al. 2008a; de Almeida Engler and Favery 2011), as revealed by histochemical analysis and the use of fluorescent markers. But cytoskeleton remodelings were different between $\mathrm{RKN}$ and $\mathrm{CN}$ feeding sites: while MTs and actin microfilaments were disrupted in syncytia, in GC a functional mitotic apparatus and disorganized cortical MTs and actin filaments were still present. These cytoskeleton changes may be triggered by ABPs and MAPs, whose transcript abundance appears to vary following nematode infection. Indeed, upregulation of membrane-anchored actin-nucleating formins AtFH1, AtFH6, and AtFH10, that may participate in actin cytoskeleton remodeling, was observed in developing feeding sites in Arabidopsis (Favery et al. 2004; Jammes et al. 2005; Barcala et al. 2010). Upregulation of five of the seven Arabidopsis actin-depolymerizing factor (ADF) promoters also occurs in expanding GC and/or surrounding cells 
(Fuller et al. 2007; Clément et al. 2009), and increased expression of ADF3 was observed in CNinduced syncytia (Fuller et al. 2007). Experimental evidence has validated the direct involvement of the ADF2 gene in GC formation and RKN development in Arabidopsis (Clément et al. 2009). The Arabidopsis MAP65-3 is essential for the development of GC induced by $M$. incognita (Caillaud et al. 2008c). Detailed functional analyses of MAP65-3, which plays a key role in the organization of microtubule arrays during both mitosis (spindle morphogenesis) and cytokinesis (phragmoplast expansion) in dividing plant cells, showed that this protein was associated with mini cell plates formed between daughter nuclei during cytokinesis initiation in developing GC. In the absence of MAP65-3, GC started to develop but accumulation of mitosis defects (CW stubs and connected nuclei) during repeated events of nuclear division prevented the development of functional feeding cells. GC did not complete their differentiation, impairing the maturation of the infecting nematodes (Caillaud et al. 2008c).

To our knowledge, cytoskeleton rearrangements in gall cells following infection with $P$. brassicae are not documented. Strong downregulation of both $\alpha$ and $\beta$-tubulins was, however, observed following infection, suggesting MT rearrangements are associated with clubroot disease (Devos et al. 2006). And, the upregulation in inoculated Brassica napus of a profilin, an ABP having effects on the dynamics of actin microfilaments, suggest that the plant actin cytoskeleton may also be targeted by P. brassicae (Cao et al. 2008).

\section{Root Pathogens Hijack Cell Cycle Regulators}

As mentioned earlier, GC initiation implies cell cycle reentry of a group of selected provascular cells that will undergo successive mitotic events leading to multinucleated cells. In parallel, GCsurrounding parenchyma vascular cells and xylem elements will divide extensively, causing a root swelling leading to gall formation. The $\mathrm{CN}$-induced feeding site formation also involves reentry of the cell cycle of neighboring cells, which are then incorporated into the syncytium through CW dissolution. The use of the cell cycle inhibitors hydroxyurea and oryzalin arrested nematode feeding site development (de Almeida Engler et al. 1999). Promoter-driven GUS expression and in situ hybridization in Arabidopsis confirmed the RKN and $\mathrm{CN}$ recruitment of cell cycle regulators, two mitotic cyclins (AtCYCA2;1 and AtCYCB1;1), and two cyclin-dependent kinases (AtCDKA;1 and AtCDKB1;1), at early stages of the interactions (Niebel et al. 1996; de Almeida Engler et al. 1999). The upregulation of mitotic cyclins of the A- and B-type by RKN, which are involved in S-phase progression and control $\mathrm{G}_{2} / \mathrm{M}$ and mitotic transitions, respectively (Inzé and De Veylder 2006), and CDKs has been confirmed in different microarray analysis (Jammes et al. 2005, Barcala et al. 2010; Ibrahim et al. 2011). Recent results show that silencing of CDKA;1 reduced Arabidopsis susceptibility to both RKN and CN (Van de Cappelle et al. 2008). In plants, mitotic cyclins of the D-type control progression through the G1 and into the S phases (Inzé and De Veylder 2006). Transcriptome analysis revealed upregulation of the Arabidopsis cyclin D3;2 in hand-dissected galls (Jammes et al. 2005), and in tomato, the cyclin D3;2 encoding gene was shown to be the only mitotic cyclin induced specifically in microdissected GC (Ramsay et al. 2004). The Arabidopsis CKS2, a regulator of CDKs that controls cell division, is also expressed in both GC and syncytia (de Almeida Engler et al. 2011). Induction of several other positive cell cycle regulator genes such as the Arabidopsis PROLIFERA(Huang et al. 2003; Barcala et al. 2010), the tomato, and cowpea PHI-1 (Fosu-Nyarko et al. 2009; Das et al. 2010), or soybean nuclear DBF2-related protein kinases (Ibrahim et al. 2011), have been reported during early stages of the interaction with RKN. Plant infection by $P$. brassicae leads to the neo-formation of a meristem-like tissue. Arabidopsis 
transcriptome analysis confirmed that cell cycle genes, including several cyclins, were upregulated during the earlier time points following P. brassicae infection (Siemens et al. 2006). And, the use of the AtCYCB $1 ; 1:: G U S$ construct illustrated the local re-initiation of cell division in the root cortex from the first days after P. brassicae inoculation (Devos et al. 2006).

In both GC and syncytia, nuclei are enlarged and amoeboid, and DNA endoreduplication may occur to sustain the enhanced metabolic demands associated with the interaction (de Almeida Engler et al. 1999; Wildermuth 2010; de Almeida Engler et al. 2011). Strong accumulation of the mitotic inhibitor CCS52a transcripts has been reported in RKN-induced GC (Koltai et al. 2001; Favery et al. 2002). Preliminary experiments suggest a role for CCS52a in CN growth and development (Gheysen and Mitchum 2009). The Arabidopsis CPR5 gene, which also regulates endoreduplication and cell division (Kirik et al. 2001), is upregulated in root-knots as well (Jammes et al. 2005). But to date, endoreduplication processes associated with plant-nematode interactions remain poorly understood.

\section{Severe Cell Wall Remodeling Is Associated with Feeding Site Formation}

The plant CW is a dynamic, highly organized extra-cytoplasmic matrix made of various polysaccharides (mainly cellulose, hemicelluloses, and pectin), structural proteins, and aromatic substances and is constantly remodeled and restructured during growth and development (Carpita and Gibeaut 1993). Extensive CW modifications are required to build up a GC and syncytia (Sobczak et al. 2011). In addition to CW changes mediated by the plant enzymes during GC or syncytium formation, RKN and $\mathrm{CN}$ themselves secrete a number of CW-modifying enzymes. For example, the nematodes encode an array of CW-modifying proteins that function in the host cell and host tissues during nematode penetration, migration, and the early stages of feeding site formation.

In order to sustain the remarkable cell expansion associated with the development of the hypertrophied $\mathrm{GC}, \mathrm{CW}$ relaxation by $\mathrm{CW}$-loosening enzymes is required. Whole transcriptome analysis confirmed that several classes of genes coding for CW loosening enzymes including expansins, endoglucanases, xyloglucan endotransglycosylases (XETs), pectate lyases, and polygalacturonases are activated early in response to infection (Jammes et al. 2005; Fosu-Nyarko et al. 2009; Barcala et al. 2010; Ibrahim et al. 2011). In Arabidopsis, $\alpha$-expansins and pectate lyases account for the most strongly upregulated genes within the gall. The use of promoter fusions with the GUS reporter gene and in situ hybridization confirmed expression in GC of Arabidopsis and tobacco endoglucanases (Goellner et al. 2001; Mitchum et al. 2004; Wang et al. 2007), of an Arabidopsis pectin acetylesterase (Vercauteren et al. 2002), and a tomato expansin (Gal et al. 2006). Silencing expression of tomato EXPA5 affected the ability of the nematode to complete its life cycle (Gal et al. 2006). Other characteristic features of GC are an important CW thickening and formation of CW ingrowths, meaning synthesis and deposition of new CW material are also necessary. Several genes encoding cellulose synthases, CW structural proteins, or other CW component synthesizing enzymes are also differentially regulated during plant-RKN interactions (Jammes et al. 2005, Ibrahim et al. 2011; Sobczak et al. 2011). As an example, the upregulation of the cross-linking structural extensin proteins has been well documented (Niebel et al. 1993; Van der Eycken et al. 1996).

Syncytium development is also associated with extensive CW modifications. The CN feeding structure forms by the dissolution of plant $\mathrm{CW}$ and membranes between adjacent cells, and $\mathrm{CW}$ expansion. In addition, syncytial CW thicken and CW ingrowths form, which implies CW synthesis (Sobczak et al. 2011). Transcriptome analysis has confirmed tremendous regulation in the expression of genes encoding CW-degrading enzymes in Arabidopsis and soybean infected with Heterodera 
spp. (Ithal et al. 2007b; Tucker et al. 2007, 2011; Szakasits et al. 2009). The crucial role played in syncytium development by the plant host expansins (Wieczorek et al. 2006; Wieczorek and Grundler 2006; Fudali et al. 2008) and endoglucanases (Karczmarek et al. 2008; Wieczorek et al. 2008) has been particularly well documented.

During $P$. brassicae-induced club formation, cell division is followed by an extension of the newly formed cells. Arabidopsis clubroot microarray analysis highlighted upregulation of genes encoding CW-loosening enzymes such as $\alpha$-expansins (Siemens et al. 2006). The action in gall cells of the CW-loosening XETs on CW expansion has also been documented (Devos et al. 2005).

\section{Phytohormones Regulating Development and Defense May Control Feeding Site Formation}

Plant hormones are involved in all aspects of plant growth and developmental processes as well as responses to environmental biotic and abiotic stresses. Auxin is a key player of plant organogenesis through regulation of cell division, polarity and extension, and cell fate determination. Auxin content may be increased in GC and this hormone would play a critical role during feeding site formation. Nematodes themselves could secrete auxin within the host cell (De Meutter et al. 2005). Microarray analyses reveal activation of genes responsible for auxin homeostasis and auxin-responsive genes, while repressors of auxin responses are downregulated in Arabidopsis, supporting the role of auxin in the successful establishment of RKN (Barcala et al. 2010). Histochemically, activation of auxinresponsive promoter GH3 and DR5 could be confirmed in nascent feeding cells (Hutangura et al. 1999; Karczmarek et al. 2004). And induction in RKN feeding sites of AUX1 and AtAUX4/LAX3 encoding putative auxin transporters has been reported consistently (Mazarei et al. 2003; Hammes et al. 2005; Jammes et al. 2005). In addition, depletion in Medicago truncatula roots of flavonoids, which are auxin transport regulators playing a potential role in secondary root organogenesis, affected $M$. javanica feeding site morphology (Wasson et al. 2009). But to date, only one auxin mutant, the tomato diageotropica, has been reported to alter RKN parasitism (Richardson and Price 1984). Promoting cell division and regulating cell differentiation, cytokinins have been associated with important roles in shoot and root development. More particularly, cytokinins may be involved in cyclin induction and favor cell cycle reentry. Nematodes appear to secrete biologically active cytokinins (Bird and Loveys 1980; De Meutter et al. 2003), and increase in the general content in cytokinins in GC could be measured (Bird and Loveys 1980), suggesting these hormones could play crucial functions in GC formation. Cytokinin-responsive genes, such as ARR5, are activated in the nascent gall (Lohar et al. 2004). However, this gene is repressed in GC sensu stricto and in the mature gall. Thus, cytokinins can play a role either as stimulator or inhibitor of cell division. In addition, hairy roots overexpressing a cytokinin oxidase, responsible for cytokinin degradation, were shown to be more resistant to RKN (Lohar et al. 2004). More recently, a general downregulation of a negative regulator of cytokinin signaling was observed in microdissected GC (Barcala et al. 2010).

Other mitogenic phytohormones, the small signaling peptides phytosulfokines (PSKs), could also trigger GC differentiation. While a downregulation of genes encoding PSKs was detected in Arabidopsis (Jammes et al. 2005), a strong induction of a gene coding for a PSK has been observed in RKN-challenged soybean roots (Ibrahim et al. 2011). Functional analysis of PSK and their receptor PSKR1 in Arabidopsis showed that the expression of these genes were restricted to the GC surrounding cells. Interestingly pskrl mutants presented a defect in GC expansion, leading to increased nematode resistance (Favery, unpublished).

Signaling pathways of the phytohormones salicylic acid (SA), ethylene (ET), and jasmonic acid (JA) that control aspects of plant development and defense responses may also be targeted by RKN 
for successful induction or maintenance of feeding sites. External application of SA, JA, ET, or analogs, or chemical treatments to affect synthesis of these hormones, influenced host susceptibility to RKN (Cooper et al. 2005; Bhattarai et al. 2008; Fujimoto et al. 2011; Nahar et al. 2011). Transgenic tobacco plants expressing NPR1, a positive regulator of the SA pathway showed a decrease in the number of root galls and egg masses following $M$. incognita inoculation, when compared to wildtype plants (Priya et al. 2011), and accordingly, the overexpression in rice plant of $N a h G$, expressing a bacterial salicylate hydroxylase that degrade SA, are slightly more sensitive to $M$. graminicola (Nahar et al. 2011). Silencing the rice OsEIN2b, a component of the ET-signaling pathway, also enhanced susceptibility to RKN (Nahar et al. 2011). In rice, the JA biosynthesis mutant hebiba is more susceptible toward $M$. graminicola (Nahar et al. 2011). In tomato, results suggest, however, that host susceptibility requires an intact JA signaling pathway for early steps of the feeding site formation (Bhattarai et al. 2008). Generally, the different transcriptomic analyses show a repression of transcription factors of the WRKY family that act downstream of these hormones and of several SA-, ET-, and JA-responsive genes (such as the pathogenesis-related genes, PRs) to suppress plant defenses and allow RKN biotrophy (Jammes et al. 2005, Barcala et al. 2010; Hamamouch et al. 2011; Ibrahim et al. 2011).

Because of the complexity of hormone signaling pathways, the existing synergistic and antagonistic cross talks within these pathways, and the diversity of the genes they may control, it remains difficult to elucidate the exact role played by phytohormones during feeding cell ontogenesis and gall formation in the different plant hosts.

Similarly, genome-wide gene expression profiling in $\mathrm{CN}$-induced syncytia revealed a number of genes associated with the biosynthesis and signaling of auxin and to a lesser extent ET, gibberellins, JA, and cytokinin (Ithal et al. 2007b; Szakasits et al. 2009). An increase of local auxin in the syncytium was first demonstrated by increasing GUS activity in the AUX1::GUS transgenic Arabidopsis plants upon H. schachtii or infection (Mazarei et al. 2003). In support, the artificial auxin-responsive promoter element DR5 was highly activated in the syncytium after $H$. schachtii infection (Karczmarek et al. 2004). The central role that auxin plays in the establishment of the syncytium was revealed by data showing that mutants deficient in auxin signaling and transport pathways negatively impact parasitism success and syncytium development (Grunewald et al. 2009). Similarly, ET was found to be necessary for proper syncytium formation and mediating plant susceptibility. Functional characterizations of Arabidopsis mutants that overproduce ET (eto1-1, eto2, and eto3) were found to be hypersusceptible to $H$. schachtii. In contrast, mutants that are ET-insensitive (etr1-1, ein2-1, ein3-1, eirl-1, and axr2) were less susceptible to $H$. schachtii, indicating that ET signal transduction positively impacts plant susceptibility to $\mathrm{CN}$ (Wubben et al. 2001). The role of ET in syncytium development was supported by the histological analysis of infected eto2 roots showing expansion of the feeding site structure and extensive $\mathrm{CW}$ dissolution between fused cells (Goverse et al. 2000). However, direct evidence supporting roles of other phytohormones in syncytium formation and function are lacking.

In $P$. brassicae, it has been shown that plasmodia are able to produce cytokinin, which are released into the host cytoplasm, inducing host cell division (Devos et al. 2006). Availability of hormone-responsive promoters DR5 and ARR5 allowed detection of strong auxin and cytokinin responses, respectively, in the root gall on Arabidopsis. An increase in concentration of active forms of both auxin and cytokinin could be quantified in B. rapa (Devos et al. 2005). Furthermore, data from transcriptome analysis of Arabidopsis clubroots show strong regulation of genes involved in auxin and cytokinin homeostasis (Siemens et al. 2006). In Arabidopsis, genes involved in auxin synthesis, transport, and responses are strongly upregulated. Regulation of nitrilase genes involved in auxin synthesis has also been reported in B. rapa (Ando et al. 2008). The alhl mutant of 
Arabidopsis, which may be affected in auxin transport, shows resistance responses to $P$. brassicae (Devos et al. 2006). As observed in root-knot, cytokinin oxidases have been shown to be particularly downregulated in infected tissues. Again, overexpression of $C K X s$ in transgenic Arabidopsis results in increased resistance to $P$. brassicae (Siemens et al. 2006). It is accepted that early cytokinin accumulation promotes cell division, allowing club ontogenesis. Auxin could in the first phases of the interaction induce cell elongation through upregulation of XETs, and in the later phase, the impressive upregulation of auxin biosynthesis pathways and transport might lead to cell degradation for resting spore release. However, results remain contradictory and hormone actions may vary depending on plant host, protist ecotypes, and stage of disease development. In addition, abscisic acid, ET, and jasmonate may also play roles during root disease. Two recent reviews summarized the current knowledge on hormonal changes and signals during clubroot development (Ludwig-Müller and Schuller 2008; Ludwig-Müller et al. 2009).

\section{Role of miRNAs in Feeding Site Formation and Function}

Genome-wide gene expression profiling has revealed that unique changes of plant cell fate associated with nematode-induced feeding site formation involve extensive gene expression changes, including substantial downregulation of genes at the mRNA level in parasitized plant cells and roots (Jammes et al. 2005; Alkharouf et al. 2006; Ithal et al. 2007b; Klink et al. 2009; Barcala et al. 2010). While the genetic networks underlying gene expression regulation in feeding sites are unknown, increasing evidence supports fundamental roles of small RNA molecules as powerful regulators of gene expression in living cells. Endogenous small RNAs are 20-24 nucleotide molecules that regulate gene expression through posttranscriptional gene silencing, translational repression and heterochromatin modification (Vaucheret 2006). On the basis of their precursor structures and biogenesis, small RNAs can be divided into two main classes, microRNAs (miRNAs) and small interfering RNAs (siRNAs). siRNAs were identified in animals, plants, bacteria, and fungi (Grosshans and Filipowicz 2008), an indication of both the significance and the ancient origin of these regulatory molecules. With the advent of high-throughput sequencing technology of small RNA libraries, a new era for small RNA exploration has arrived. Analysis of small RNA components at genomic scales revealed the diversity and the complexity of these molecules (Schwach et al. 2009). Complexity of siRNAs arises from their diverse origins, which include coding genes, pseudogenes, repetitive sequences such as transposons and retrotransposons, tandem and inverted repeats, and intergenic regions (Lu et al. 2005).

miRNAs initially have been shown to be involved in the regulation of a variety of plant developmental processes including phase transition, hormone synthesis and signaling, pattern formation, and morphogenesis (Chen 2009). Recent studies indicate that miRNAs and small endogenous RNAs also are involved in biotic stress responses in plants. For example, Arabidopsis miRNA393 contributes to resistance against the virulent Pseudomonas syringae pv. tomato strain DC3000 (Pto DC3000) by repressing auxin signaling (Navarro et al. 2006). In contrast, transgenic plants overexpressing miRNA398b or miRNA773 showed increased susceptibility to both virulent and nonvirulent strains of $P$. syringae (Li et al. 2010). In addition, alteration of miRNA gene expression was observed upon infection by various plant pathogens, including viruses (He et al. 2008), fungi (Lu et al. 2007), bacteria (Fahlgren et al. 2007), and herbivorous insects (Pandey et al. 2008). Pathogen-induced accumulation of a natural antisense transcript-associated siRNA was found to inhibit a negative regulator of the resistance gene RPS2-mediated race-specific resistance pathway (Katiyar-Agarwal et al. 2006). Similarly, endogenous long siRNAs (30-40 nt) were induced upon bacterial infection 
and contributed to host defense responses to the pathogen (Katiyar-Agarwal et al. 2007). Consistent with the role of small RNAs in the regulation of plant immune responses, Arabidopsis mutants deficient in siRNA or miRNA biogenesis were affected in their susceptibility to bacteria (Navarro et al. 2008). Collectively, these emerging data indicate that small RNA-mediated gene regulation is a fundamental regulatory mechanism during plant-pathogen interactions.

Recent studies revealed essential roles of small RNA pathways in cell specification. For example, it has been demonstrated that small RNA pathways control male and female gamete formation (Olmedo-Monfil et al. 2010; Ron et al. 2010) and phloem function (Buhtz et al. 2008). Interestingly, small RNAs have been shown to control the formation and development of the nitrogen-fixing root nodule, a de novo organ formed in response to Rhizobium bacteria (Combier et al. 2006; Boualem et al. 2008; Lelandais-Briere et al. 2009). As a first step of investigating the potential implication of small RNA molecules in mediating gene regulation processes that are of importance for the formation of the syncytium, CN susceptibility of Arabidopsis mutants of genes involved in the biogenesis and production of small RNAs was examined (Hewezi et al. 2008a). Interestingly, several DICER-like $(d c l)$ and RNA-dependent RNA polymerase $(r d r)$ mutants showed significant decreases in nematode susceptibility relative to the wild type, suggesting a crucial role of small RNAs in mediating gene regulation processes that are involved in plant-nematode interactions. In addition, generation of small RNA libraries from Arabidopsis roots harvested at 4 and 7 dpi post $H$. schachtii infection led to the identification of new endogenous siRNAs and known miRNAs that are differentially expressed in response to $H$. schachtii infection (Hewezi et al. 2008a). Similar to temporal changes of miRNA expression levels in response to biotic and abiotic stress treatments (Bari et al. 2006; Navarro et al. 2006; Sunkar et al. 2006; Navarro et al. 2008), the differentially expressed miRNAs identified in that study were found to be either downregulated or unchanged at an early stage of infection, that is, $4 \mathrm{dpi}$, but at the $7 \mathrm{dpi}$ time point, these miRNAs showed significant up- or downregulation. However, it is unlikely that the observed downregulation of miRNA at the early stage of $\mathrm{CN}$ infection is a general characteristic of miRNA response to CN parasitism because recently, two additional Arabidopsis miRNAs were found to be induced in the early developing $H$. schachtii-induced syncytia (Hewezi and Baum 2012; Hewezi et al. 2012).

Consistent with the critical role that the phytohormone auxin plays in syncytium initiation and formation (Goverse et al. 2000), it was found that miR160 and miR167, which target five auxin response factor genes ( $A R F 6, A R F 8, A R F 10, A R F 16$, and $A R F 17)$, were downregulated in response to $H$. schachtii at the early stage of infection and that this downregulation was accompanied by significant upregulation of the ARF target genes, enabling the control of early auxin-responsive gene expression in the feeding sites. One of the common alterations in root systems associated with syncytium development is the lateral root formation around the syncytium. The miR164 could be one of the main players in this context. It acts as a negative regulator of auxin-mediated lateral root development by controlling mRNA abundance of NAC1, which functions in transmitting auxin signals for Arabidopsis lateral root development (Xie et al. 2000). Downregulation of miR164 coupled with strong upregulation of NACl up to 7 days post $H$. schachtii infection suggests that active auxin signal transduction associated with lateral root induction around the syncytium is connected to localized auxin increase in the feeding sites (Hewezi et al. 2008a). The finding that miRNAs are involved in developmental and biological processes related to those implicated in syncytium formation and function gives rise to the question whether spatial regulation of miRNA expression contributes to syncytial cell differentiation and development. In this context, miR396 was identified as a potentially interesting regulator of target gene expression during nematode parasitism (Hewezi et al. 2008a). miR396 regulates the expression of seven growth regulating transcription factor genes (GRFs) (Jones-Rhoades and Bartel 2004), which are known to act in a functionally 
redundant fashion to positively control cell proliferation and size in leaves (Kim et al. 2003; Kim and Kende 2004; Horiguchi et al. 2005; Kim and Lee 2006). Very recently, the miR396/GRF regulatory module was shown to have vital roles in controlling developmental events during plant-pathogen interactions (Hewezi and Baum 2012; Hewezi et al. 2012). Promoter activity analyses together with qPCR quantification revealed that miR396 expression characteristics in the syncytium clearly delineate the induction/formation phase from the maintenance phase of the syncytium and that the switch of one phase to the other appears to be mediated through miR396. GRF1 and GRF3 as the main targets of miR396 in roots were found to be predominantly active in syncytia during all parasitic stages but were posttranscriptionally silenced when miR396 abundance increased during the onset of the maintenance phase. The importance of the coordinated regulation of miR396 and GRF1 and $G R F 3$ for normal root development is supported by the data showing that overexpression of miR396 in Arabidopsis as well as its target genes GRF1 and GRF3 significantly reduces root length. The significance of this synchronized regulation for correct cell fate specification and differentiation in the developing syncytium is further supported by the data showing that miR396 overexpression in Arabidopsis as well as modulations of GRF1 and GRF3 expression dramatically limit plant susceptibility to the $H$. schachtii. Reduced susceptibility was not associated with low nematode penetration rates but rather was associated with arrested nematode development during an early stage of infection and with reduced syncytium size. In addition, genome-wide expression profiling revealed a large number of GRF-regulated genes that are involved in a wide range of biological and developmental processes. Interestingly, the miR396/GRF regulatory module can change the expression of $44 \%$ of the more than 7000 genes that change expression in the Arabidopsis syncytium (Szakasits et al. 2009). In conclusion, these data establish miR396 as a powerful regulator targeted by the parasitic nematodes to drive presyncytial cells toward novel developmental pathways required for successful syncytium formation and maintenance.

\section{Nematode Effectors That Alter Root Cell Development during Parasitism}

Various molecular proteomic and transcriptomic analysis on nematode esophageal secretions have been used to discover genes encoding effector proteins potentially involved in parasitism (Bellafiore et al. 2008; Davis et al. 2008). And new perspectives arise from the availability of nematode genomes (Bird et al. 2009). Among nematode secreted proteins are many CW-degrading or modifying enzymes. Others may be nucleus-targeted and could bind to nucleotides and influence gene expression. These secretions could also interact with host proteins or mimic plant proteins or other signaling molecules, allowing substantial alterations of plant physiology (Gheysen and Mitchum 2011).

Plant CW represents the main barrier for successful penetration and migration of nematodes throughout root tissues. CW-degrading or -modifying enzymes may account for the RKN and $\mathrm{CN}$ parasitic ability, allowing the impressive $\mathrm{CW}$ modifications or degradation required for GC or syncytia ontogenesis. Thus, there is no surprise that these proteins compose a substantial portion of nematodes secretions; and their diversity is unique in the animal kingdom (Davis et al. 2008; Davies et al. 2011). Genes encoding these enzymes could have been acquired through different events of lateral gene transfers from different bacteria (Danchin et al. 2010). One remarkable example of a functionally characterized $\mathrm{CN}$ effector protein with function in host $\mathrm{CW}$ modification is the cellulose-binding protein (CBP) from $H$. schachtii (Hewezi et al. 2008b). This CBP has a unique structural feature in that it consists only of a signal peptide for secretion and a cellulose-binding domain (CBD) without a catalytic domain. The CBD is usually found in cellulolytic enzymes, 
where it mediates the attachment of the enzymes to the insoluble cellulose substrate, while a catalytic domain is responsible for hydrolytic activity. Because Heterodera CBPs do not contain catalytic domains, their functions were enigmatic, but a multifaceted functional characterization approach uncovered their mode of action. The CBP gene is expressed in the nematode's secretory subventral gland cells, consistent with a role during migration or early syncytium formation. In planta overexpression of the $C B P$ gene produced plants with increased root length and increased susceptibility to $\mathrm{H}$. schachtii infection but producing feeding sites of the same size as the wild type. Because of the absence of the catalytic domain, CBP has been hypothesized to act in concert with host proteins to exert its function. Using yeast two-hybrid screens, CBP was found to interact with Arabidopsis pectin methylesterase protein 3 (PME3), a CW-localized enzyme. Interestingly, $\mathrm{PME}$ activity increased in $C B P$-overexpressing plants, indicating that $\mathrm{CBP}$ acts in activating PME3 during the infection process. As hypothesized, overexpression of $P M E 3$ mimicked the phenotypes of $C B P$-overexpressing plants of longer roots and increased nematode susceptibility, whereas a pme3 mutant exhibited the opposite phenotypes. In addition, expression of $C B P$ in the pme 3 mutant background confirmed that PME3 is required for the CBP overexpression phenotypes, but it also revealed that PME3 is not the sole host factor responsible. In short, after studying PME3 functions, it seems most likely that a reduction of $\mathrm{CW}$ pectin methyl esterification through increasing PME3 activity as a result of its interaction with CBP augments the access of other CW-modifying enzymes to the plant CW of presyncytial cells, thereby facilitating parasitic establishment in the root system.

Another $\mathrm{CN}$ effector that acts in activating $\mathrm{CW}$-modifying enzymes through its interaction with host factors is the 19C07 protein from H. schachtii. 19C07 was shown to interact with the auxin influx transporter LAX3 (Lee et al. 2011), known to activate CW-digesting enzymes (Swarup et al. 2008). LAX3 plays a key role in lateral root emergence by directing auxin signaling that activates the expression of CW-modifying enzymes to root cells overlaying lateral root primordial where it is predominantly expressed, permitting lateral roots to emerge. The interaction with LAX3 seems to be one mechanism by which $\mathrm{CN}$ alters auxin flow into root cells for syncytium formation. Consistent with the suggestion that 19C07 functions in increasing the activity of LAX3, overexpression of $19 C 07$ in Arabidopsis increased the rate of lateral root emergence, an indication of increasing auxin influx. Moreover, nematode infection promotes lateral root formation in the aux //lax3 double and aux1/lax1/lax2/lax3 quadruple mutants at the site of infection (Lee et al. 2011). The novel $H$. schachtii effector gene $10 A 06$ also was shown to impact root development. Constitutive expression of 10 A06 in Arabidopsis produced plants with up to $28 \%$ increase in root length (Hewezi et al. 2010). Interaction of $10 \mathrm{~A} 06$ with Arabidopsis spermidine synthase 2 (SPDS2), a key enzyme involved in polyamine biosynthesis, induce changes in polyamine metabolism and catabolic pathway in the syncytium. These changes resulted in both activation of cellular antioxidant machinery and inhibition of SA-dependent defense signaling concomitant with increased susceptibility of 10A06overexpressing plants to $H$. schachtii, Pseudomonas (Pst DC3000), and cucumber mosaic virus Y (Hewezi et al. 2010). It appears most likely that inhibition of host defense responses in the developing syncytium along with initiation of a protective antioxidant environment to protect the developing syncytia against reactive oxygen species produced by the host as common feature of plant responses to plant-parasitic nematode infection in both compatible and incompatible interactions (Waetzig et al. 1999) are mechanisms by which $10 \mathrm{~A} 06$ contributes to $\mathrm{CN}$ parasitism.

Despite the fact that both $H$. schachtii and $H$. glycines have very similar effector repertoires, $H$. schachtii infects and efficiently reproduces on Arabidopsis roots, while $H$. glycines is rarely able to complete the life cycle on this model plant. The molecular basis for these differences remains unknown. A recent report has provided new evidence that sequence divergence between certain 
$\mathrm{CN}$ effector protein orthologs could contribute to host specificity (Hewezi and Baum 2010). In this study, it was found that ectopic expression of $\mathrm{H}$. glycines $10 \mathrm{AO6}$ ( $\mathrm{Hg}$-10A06) in the nonhost Arabidopsis plants affected root length to a much lesser degree when compared with Arabidopsis plants overexpressing $10 A 06$ form $\mathrm{H}$. schachtii (Hs-10A06), although both orthologs share high sequence identity of $86 \%$. In addition, Hg-10A06 was found to interact with Arabidopsis SPDS2, while its ability to interact with SPDS2 decreased by about fivefold when compared with Hs-10A06. Taken together, these data suggest that effector functions could be involved in determining host range and that the root phenotypes obtained in 10A06 overexpressing plants are associated with host factor recognition and more specifically polyamine signaling pathways. The influence of polyamines on root emergence, formation, and development has been shown in numerous plant species (Kakkar et al. 2000; Bais and Ravishankar 2002).

It has been shown that RKN and $\mathrm{CN}$ secrete effectors with sequence similarity to endogenous host plant proteins. These include, for example, chorismate mutases (Lambert et al. 1999; Bekal et al. 2003; Huang et al. 2005; Vanholme et al. 2009), the expansin-like proteins (Qin et al. 2004; Abad et al. 2008; Hewezi et al. 2008b; Danchin et al. 2010), the CN CLAVATA3-like (CLE) peptides (Wang et al. 2005, 2010; Lu et al. 2009) and annexins (Patel et al. 2010). The CLE genes were identified first in plant species where they regulate a wide range of biological processes including meristem function, organ size, apical dominance, and root development (Strabala et al. 2006; Fiers et al. 2007; Oelkers et al. 2008). Direct evidence for the implication of CLE genes in Arabidopsis root growth and differentiation were provided through overexpression and/or direct application of synthetic 14-amino acid peptides corresponding to the CLE motif (CasamitjanaMartinez et al. 2003; Hobe et al. 2003; Fiers et al. 2004, 2005). While it was assumed that CLE genes are a plant-specific gene family, surprisingly sequence analyses of cDNA clones generated from microaspirated esophageal gland cell cytoplasm of $H$. glycines led to the discovery of the first CLE-like gene (HgSYV46) outside of plants (Wang et al. 2001). Subsequent functional analysis of HgSYV46 through overexpression in Arabidopsis wild-type and clv3 mutant backgrounds provided the first evidence that $\mathrm{CN} \mathrm{HgSYV46}$ has functional similarity to Arabidopsis CLE genes (Wang et al. 2005). In addition, recent studies have reported the existence of CLE-like genes in G. rostochiensis (GrCLEs) (Lu et al. 2009) and H. schachtii (HsCLEs) (Wang et al. 2011). While the HsCLE genes are structurally similar to those identified in H. glycines, GrCLEs have a novel structural feature consisting of several CLE motifs organized in tandem repeats ( $\mathrm{Lu}$ et al. 2009). This gives rise to the possibility that multiple CLE motif-containing proteins could be processed in a way to generate a variety of CLE peptides that stimulate distinct CLE signaling pathways that act antagonistically or cooperatively as in the case of plant CLEs (Whitford et al. 2008). Similar to $H g S Y V 46$, overexpression of GrCLEs produced phenotypes resembling those of plant CLE genes in Arabidopsis, and Gr-CLE proteins could complement the Arabidopsis clv3-2 mutant phenotype (Lu et al. 2009). Interestingly, overexpression of Gr-CLEs containing single or multiple CLE motifs in Arabidopsis and potato hairy roots produced a short root phenotype. The short root phenotype can also be generated in vitro by exogenous application of synthetic Gr-CLE peptides to Arabidopsis and potato roots (Lu et al. 2009)

Overall, these data raise the question of how CLE peptides contribute to the redifferentiation of mature root cells to form the very specialized and novel syncytial cell type. It has been proposed that the secreted CLE-like peptides function as peptide mimics of particular host CLE factors to drive the presyncytial cells toward specific and unique developmental programs required for the initiation of the feeding cells (Mitchum et al. 2008). This suggestion is further supported by recent studies reporting that signaling of stem cell maintenance in Arabidopsis shoot and root meristems is regulated by common regulatory mechanisms (Sarkar et al. 2007), including a CLAVATA 
(CLV)-like pathway (Casamitjana-Martinez et al. 2003), and that the receptor kinase family members CORYNE (CRN) and CLV2 implicate CLE signaling in Arabidopsis roots (Fiers et al. 2005; Muller et al. 2008). In support, it has been recently shown that CLV2 and CRN are involved in mediating nematode CLE signaling in Arabidopsis roots (Replogle et al. 2011). Interestingly, clv2-1 and crn-1 mutants were found to be resistant to exogenous application of the synthetic nematode peptides HgCLE, HsCLE1, and HsCLE2. Likewise, overexpression of HgCLE, HsCLE1, and HsCLE2 genes in the $c l v 2-1$ and $c r n-1$ mutant backgrounds abolished the phenotypes observed in the transgenic plants overexpressing these CLE genes in wild-type backgrounds (Wang et al. 2005, 2011). Both receptors were found to be expressed in the nematode-induced syncytia and manipulation of their expression impacted nematode susceptibility and syncytium size (Replogle et al. 2011). While these results suggest that perception of nematode CLEs by CLV2 and CRN is required for successful parasitism, biochemical data showing the localization of actual perception are lacking. Despite the fact that the exact trafficking mechanism of nematode CLE peptides to the apoplast where they function is unknown, it has been recently suggested that nematode CLEs are processed in host cells rather than in the nematodes and that the propeptides are delivered into the cytoplasm of syncytial cells, but ultimately function in the apoplast (Wang et al. 2010), consistent with their anticipated roles as ligand mimics of host CLE peptides. Further studies to identify the underlying mechanisms that integrate CLE signaling and downstream components in the developmental reprogramming of selected root cells to form the syncytium merit detailed functional studies.

The role of CLEs in plant RKN interactions is not as clear, but genome analysis reveals the presence of five and seven candidate CLE genes in $M$. incognita and M. hapla, respectively (Abad et al. 2008; Opperman et al. 2008). However, clvl mutants were not found to impacted RKN susceptibility (Favery, unpublished). Huang and collaborators presented the first evidence for a direct interaction of a $M$. incognita-secreted peptide, 16D10, having sequence similarity to the CLE motif, with a plant SCARECROW-like transcription factor (Huang et al. 2006a). SCARECROW are members of the GRAS family of transcription factors, regulating root cell division and are required for root growth and morphogenesis (Pysh et al. 1999). Expression of the 16D10 effector in Arabidopsis stimulated root growth (Huang et al. 2006a). And silencing RKN 16D10 through hostinduced gene silencing resulted in reduced nematode infectivity (Huang et al. 2006b). However, this peptide was not able to rescue the clv3 mutant, and its function as a plant CLE ligand mimic remains to be proven.

\section{Conclusion}

Growth and performance of root determines crop yield and is significantly influenced by microorganisms colonizing the rhizosphere. In the past few years, molecular and genetic approaches allowed substantial progress in our understanding of how pathogens manipulate plant hosts and their roots. The analyses at a genome-wide scale using transcriptomic approaches revealed pathogenresponsive plant genes. However, their functional analyses remain a major obstacle. In the future, a new challenge will be to integrate transcriptomic data with proteomic and metabolomic information to better identify aspects of hosts' physiology corrupted by pathogens. One other future aspect of research has been opened up by the increasing number of studies on pathogen secretomes. While microbial effectors of parasitism are being identified, significant progress remains to be made in characterizing the direct host targets of these secreted proteins and studying whether small RNAs function as key players. The genome sequences of pathogens such as $M$. incognita (Abad et al. 2008; http://www.inra.fr/meloidogyne_incognita), M. hapla (Opperman et al. 2008; 
http://www.hapla.org), H. glycines, and G. pallida will provide new horizons for studying plantnematode interactions. Finally, determining how a pathogen modifies root cells to serve as feeding cells will provide unique insights into fundamental cellular mechanisms in plants and will contribute to offer novel approaches to protect plants.

\section{Acknowledgments}

Our gratitude goes to Maria Manzanares-Dauleux at UMR118 INRA-Agrocampus Ouest-Université de Rennes 1, France, for the clubroot pictures, and Marie-Cécile Caillaud and Philippe Castagnone for RKN images. P.A. and B.F. team was supported by INRA, CNRS, Nice Sophia Antipolis University, the Agence Nationale de la Recherche (ANR-05-GPLA-020 "AFINDIS" and ANR-08GENM-014 "SCRIPS") grant. We apologize to all colleagues and researchers whose work has not been cited directly.

\section{References}

Abad, P. et al. (2009) Invasion, feeding and development. In: R.N. Perry, M. Moens, and J.L. Starr (eds) Root-Knot Nematodes. CAB International, Wallingford, pp. 163-181.

Abad, P. et al. (2008) Genome sequence of the metazoan plant-parasitic nematode Meloidogyne incognita. Nature Biotechnology, 26, 909-915.

Abad, P. and Williamson, V.M. (2010) Plant nematode interaction: a sophisticated dialogue. In: J.-C. Kader and M. Delseny (eds) Advances in Botanical Research. Academic Press, New York, pp. 147-192.

Alkharouf, N. et al. (2004) Analysis of expressed sequence tags from roots of resistant soybean infected by the soybean cyst nematode. Genome, 47, 380-388.

Alkharouf, N.W. et al. (2006) Timecourse microarray analyses reveal global changes in gene expression of susceptible Glycine max (soybean) roots during infection by Heterodera glycines (soybean cyst nematode). Planta, 224, 838-852.

Ando, S. et al. (2008) Plant Molecular Biology, Vol. 68. Springer, Netherlands, pp. 557-569.

Bais, H.P. and Ravishankar, G.A. (2002) Role of polyamines in the ontogeny of plants and their biotechnological applications. Plant Cell Tissue and Organ Culture, 69, 1-34.

Barcala, M. et al. (2010) Early transcriptomic events in microdissected Arabidopsis nematode-induced giant cells. The Plant Journal, 61, 698-712.

Bari, R. et al. (2006) PHO2, microRNA399, and PHR1 define a phosphate-signaling pathway in plants. Plant Physiology, 141, 988-999.

Bar-Or, C. et al. (2005) A broad characterization of the transcriptional profile of the compatible tomato response to the plant parasitic root knot nematode Meloidogyne javanica. European Journal of Plant Pathology, 111, 181-192.

Bekal, S. et al. (2003) A chorismate mutase from the soybean cyst nematode Heterodera glycines shows polymorphisms that correlate with virulence. Molecular Plant-Microbe Interactions, 16, 439-446.

Bellafiore, S. et al. (2008) Direct identification of the Meloidogyne incognita secretome reveals proteins with host cell reprogramming potential. PLoS Pathogens, 4, e1000192.

Bhattarai, K.K. et al. (2008) Tomato susceptibility to root-knot nematodes requires an intact jasmonic acid signaling pathway. Molecular Plant-Microbe Interactions, 21, 1205-1214.

Bird, A.F. and Loveys, B.R. (1980) The involvement of cytokinins in a host-parasite relationship between the tomato (Lycopersicon esculentum) and a nematode (Meloidogyne javanica). Parasitology, 80, 497-505.

Bird, D.M. et al. (2009) The genomes of root-knot nematodes. Annual Review of Phytopathology, 47, 333-351.

Boualem, A. et al. (2008) MicroRNA166 controls root and nodule development in Medicago truncatula. The Plant Journal, 54, $876-887$.

Buhtz, A. et al. (2008) Identification and characterization of small RNAs from the phloem of Brassica napus. The Plant Journal, 53, 739-749.

Caillaud, M.-C. et al. (2008a) Cytoskeleton reorganization: a key process in root-knot nematode-induced giant cell ontogenesis. Plant Signaling and Behavior, 3, 816-818. 
Caillaud, M.-C. et al. (2008b) Root-knot nematodes manipulate plant cell functions during a compatible interaction. Journal of Plant Physiology, 165, 104-113.

Caillaud, M.-C. et al. (2008c) MAP65-3 Microtubule-associated protein is essential for nematode-induced giant cell ontogenesis in Arabidopsis. The Plant Cell, 20, 423-437.

Cao, T. et al. (2008) Proteome-level changes in the roots of Brassica napus as a result of Plasmodiophora brassicae infection. Plant Science, 174, 97-115.

Carpita, N.C. and Gibeaut, D.M. (1993) Structural models of primary cell walls in flowering plants: consistency of molecular structure with the physical properties of the walls during growth. The Plant Journal, 3, 1-30.

Casamitjana-Martinez, E. et al. (2003) Root-specific CLE19 overexpression and the sol1/2 suppressors implicate a CLV-like pathway in the control of Arabidopsis root meristem maintenance. Current Biology, 13, 1435-1441.

Chen, X. (2009) Small RNAs and their roles in plant development. Annual Review of Cell Developmental Biology, 25, $21-44$.

Clément, M. et al. (2009) Actin-depolymerizing factor 2-mediated actin dynamics are essential for root-knot nematode infection of Arabidopsis. The Plant Cell, 21, 2963-2979.

Combier, J.P. et al. (2006) MtHAP2-1 is a key transcriptional regulator of symbiotic nodule development regulated by microRNA169 in Medicago truncatula. Genes and Development, 20, 3084-3088.

Cooper, W.R. et al. (2005) Effects of jasmonate-induced defenses on root-knot nematode infection of resistant and susceptible tomato cultivars. Journal of Chemical Ecology, 31, 1953-1967.

Danchin, E.G.J. et al. (2010) Multiple lateral gene transfers and duplications have promoted plant parasitism ability in nematodes. Proceedings of the National Academy of Sciences USA, 107, 17651-17656.

Das, S. et al. (2010) Transcriptional profiling of root-knot nematode induced feeding sites in cowpea (Vigna unguiculata L. Walp.) using a soybean genome array. BMC Genomics, 11, 480.

Davies, E. et al. (2011) Degradation of the plant cell wall by nematodes. In: J. Jones, G. Gheysen, and C. Fenoll (eds) Genomics and Molecular Genetics of Plant-Nematode Interactions, Springer, New York, pp. 255-272.

Davis, E.L. et al. (2008) Parasitism proteins in nematode-plant interactions. Current Opinion in Plant Biology, 11, 360-366.

de Almeida Engler, J. et al. (1999) Molecular markers and cell cycle inhibitors show the importance of cell cycle progression in nematode-induced galls and syncytia. The Plant Cell, 11, 793-808.

de Almeida Engler, J. et al. (2011) Unravelling the plant cell cycle in nematode induced feeding sites. In: J. Jones, G. Gheysen, and C. Fenoll (eds) Genomics and Molecular Genetics of Plant-Nematode Interactions, Springer, New York, pp. 349-368.

de Almeida Engler, J. and Favery, B. (2011) The plant cytoskeleton remodelling in nematode induced feeding sites. In: J. Jones, G. Gheysen, and C. Fenoll (eds) Genomics and Molecular Genetics of Plant-Nematode Interactions. Springer, New York, pp. 369-393.

de Almeida Engler, J. et al. (2010) Plant actin cytoskeleton remodeling by plant parasitic nematodes. Plant Signaling and Behavior, 5, 213-217.

de Almeida Engler, J. et al. (2004) Dynamic cytoskeleton rearrangements in giant cells and syncytia of nematode-infected roots. The Plant Journal, 38, 12-26.

De Meutter, J. et al. (2005) Production of auxin and related compounds by the plant parasitic nematodes Heterodera schachtii and Meloidogyne incognita. Communications in Agricultural and Applied Biological Sciences, 70, 51-60.

De Meutter, J. et al. (2003) Identification of cytokinins produced by the plant parasitic nematodes Heterodera schachtii and Meloidogyne incognita. Molecular Plant Pathology, 4, 271-277.

Devos, S. et al. (2006) A hormone and proteome approach to picturing the initial metabolic events during Plasmodiophora brassicae infection on Arabidopsis. Molecular Plant-Microbe Interactions, 19, 1431-1443.

Devos, S. et al. (2005) Infection of Chinese cabbage by Plasmodiophora brassicae leads to a stimulation of plant growth: impacts on cell wall metabolism and hormone balance. New Phytologist, 166, 241-250.

Fahlgren, N. et al. (2007) High-throughput sequencing of Arabidopsis microRNAs: evidence for frequent birth and death of MIRNA genes. PLoS One, 2, e219.

Favery, B. et al. (2004) Arabidopsis formin AtFH6 is a plasma membrane-associated protein upregulated in giant cells induced by parasitic nematodes. The Plant Cell, 16, 2529-2540.

Favery, B. et al. (2002) The endosymbiosis-induced genes ENOD40 and CCS52a are involved in endoparasitic-nematode interactions in Medicago truncatula. Molecular Plant-Microbe Interactions, 15, 1008-1013.

Fiers, M. et al. (2005) The 14-amino acid CLV3, CLE19, and CLE40 peptides trigger consumption of the root meristem in Arabidopsis through a CLAVATA2-dependent pathway. The Plant Cell, 17, 2542-2553.

Fiers, M. et al. (2004) Mis-expression of the CLV3/ESR-like gene CLE19 in Arabidopsis leads to a consumption of root meristem. Gene, 327, 37-49.

Fiers, M. et al. (2007) CLE peptide ligands and their roles in establishing meristems. Current Opinion in Plant Biology, 10, 39-43.

Fosu-Nyarko, J. et al. (2009) Functional characterization of transcripts expressed in early-stage Meloidogyne javanica-induced giant cells isolated by laser microdissection. Molecular Plant Pathology, 10, 237-248. 
Fudali, S. et al. (2008) Two tomato alpha-expansins show distinct spatial and temporal expression patterns during development of nematode-induced syncytia. Physiologia Plantarum, 132, 370-383.

Fujimoto, T. et al. (2011) Expression profile of jasmonic acid-induced genes and the induced resistance against the root-knot nematode (Meloidogyne incognita) in tomato plants (Solanum lycopersicum) after foliar treatment with methyl jasmonate. Journal of Plant Physiology, 168, 1084-1097.

Fuller, V.L. et al. (2007) Differential gene expression in Arabidopsis following infection by plant-parasitic nematodes Meloidogyne incognita and Heterodera schachtii. Molecular Plant Pathology, 8, 595-609.

Gal, T. et al. (2006) Expression of a plant expansin is involved in the establishment of root knot nematode parasitism in tomato. Planta, 224, 155-162.

Gheysen, G. and Fenoll, C. (2002) Gene expression in nematode feeding sites. Annual Review of Phytopathology, 40, 191-219.

Gheysen, G. and Mitchum, M.G. (2009) Molecular insights in the susceptible plant response to nematode infection. In: R.H. Berg and C.G. Taylor (eds) Cell Biology of Plant Nematode Parasitism, Springer-Verlag, Berlin.

Gheysen, G. and Mitchum, M.G. (2011) How nematodes manipulate plant development pathways for infection. Current Opinion in Plant Biology, 14, 415-421.

Goellner, M. et al. (2001) Endo-beta-1,4-glucanase expression in compatible plant-nematode interactions. The Plant Cell, 13, 2241-2255.

Goverse, A. et al. (2000) Both induction and morphogenesis of cyst nematode feeding cells are mediated by auxin. Molecular Plant-Microbe Interactions, 13, 1121-1129.

Grosshans, H. and Filipowicz, W. (2008) Molecular biology: the expanding world of small RNAs. Nature, 451, 414-416.

Grundler, F.M.W. et al. (1998) Formation of cell wall openings in root cells of Arabidopsis thaliana following infection by the plant-parasitic nematode Heterodera schachtii. European Journal of Plant Pathology, 104, 545-551.

Grunewald, W. et al. (2009) Manipulation of auxin transport in plant roots during Rhizobium symbiosis and nematode parasitism. The Plant Cell, 21, 2553-2562.

Hamamouch, N. et al. (2011) Expression of Arabidopsis pathogenesis-related genes during nematode infection. Molecular Plant Pathology, 12, 355-364.

Hammes, U.Z. et al. (2005) Nematode-induced changes of transporter gene expression in Arabidopsis roots. Molecular PlantMicrobe Interactions, 18, 1247-1257.

He, X.F. et al. (2008) Characterization of conserved and novel microRNAs and their targets, including a TuMV-induced TIR-NBSLRR class R gene-derived novel miRNA in Brassica. FEBS Letters, 582, 2445-2452.

Hewezi, T. and Baum, T.J. (2010) Sequence divergences between cyst nematode effector protein orthologs may contribute to host specificity. Plant Signaling and Behavior, 5, 187-189.

Hewezi, T. and Baum, T.J. (2012) Complex feedback regulations govern the expression of miRNA396 and its GRF target genes. Plant Signaling \& Behavior, 7, 749-751.

Hewezi, T. et al. (2008a) Arabidopsis small RNAs and their targets during cyst nematode parasitism. Molecular Plant-Microbe Interactions, 21, 1622-1634.

Hewezi, T. et al. (2008b) Cellulose binding protein from the parasitic nematode Heterodera schachtii interacts with Arabidopsis pectin methylesterase: cooperative cell wall modification during parasitism. The Plant Cell, 20, 3080-3093.

Hewezi, T. et al. (2010) Arabidopsis spermidine synthase is targeted by an effector protein of the cyst nematode Heterodera schachtii. Plant Physiology, 152, 968-984.

Hewezi, T. et al. (2012) The Arabidopsis microRNA396-GRF1/GRF3 regulatory module acts as a developmental regulator in the reprogramming of root cells during cyst nematode infection. Plant Physiology, 159, 321-335.

Hobe, M. et al. (2003) Loss of CLE40, a protein functionally equivalent to the stem cell restricting signal CLV3, enhances root waving in Arabidopsis. Development Genes and Evolution, 213, 371-381.

Horiguchi, G. et al. (2005) The transcription factor AtGRF5 and the transcription coactivator AN3 regulate cell proliferation in leaf primordia of Arabidopsis thaliana. The Plant Journal, 43, 68-78.

Huang, G. et al. (2006b) Engineering broad root-knot resistance in transgenic plants by RNAi silencing of a conserved and essential root-knot nematode parasitism gene. Proceedings of the National Academy of Sciences, 103, 14302-14306.

Huang, G. et al. (2005) Two chorismate mutase genes from the root-knot nematode Meloidogyne incognita. Molecular Plant Pathology, 6, 23-30.

Huang, G. et al. (2006a) A root-knot nematode secretory peptide functions as a ligand for a plant transcription factor. Molecular Plant-Microbe Interactions, 19, 463-470.

Huang, X. et al. (2003) Expression of the Arabidopsis MCM gene PROLIFERA during root-knot and cyst nematode infection. Phytopathology, 93, 35-41.

Hutangura, P. et al. (1999) Auxin induction is a trigger for root gall formation caused by root-knot nematodes in white clover and is associated with the activation of the flavonoid pathway. Australian Journal of Plant Physiology, 26, 221-231. 
Ibrahim, H. et al. (2011) Analysis of gene expression in soybean (Glycine max) roots in response to the root knot nematode Meloidogyne incognita using microarrays and KEGG pathways. BMC Genomics, 12, 220.

Inzé, D. and De Veylder, L. (2006) Cell cycle regulation in plant development. Annual Review of Genetics, 40, 77-105.

Ithal, N. and Mitchum, M.G. (2011) Laser capture microdissection of nematode feeding cells. Plant Immunity, 712, 227-240.

Ithal, N. et al. (2007a) Parallel genome-wide expression profiling of host and pathogen during soybean cyst nematode infection of soybean. Molecular Plant-Microbe Interactions, 20, 293-305.

Ithal, N. et al. (2007b) Developmental transcript profiling of cyst nematode feeding cells in soybean roots. Molecular Plant-Microbe Interactions, 20, 510-525.

Jammes, F. et al. (2005) Genome-wide expression profiling of the host response to root-knot nematode infection in Arabidopsis. The Plant Journal, 44, 447-458.

Jones, M. (1981) Host cell responses to endoparasitic nematode attack: structure and function of giant cells and syncytia. Annals of Applied Biology, 97, 353-372.

Jones, M. and Dropkin, V. (1976) Scanning electron microscopy in nematode-induced giant transfer cells. Cytobios, 15, $149-161$.

Jones, M. and Payne, H. (1978) Early stages of nematode-induced giant-cell formation in roots of Impatiens balsamica. Journal of Nematology, 10, 70-84.

Jones-Rhoades, M.W. and Bartel, D.P. (2004) Computational identification of plant MicroRNAs and their targets, including a stress-induced miRNA. Molecular Cell, 14, 787-799.

Kageyama, K. and Asano, T. (2009) Life cycle of Plasmodiophora brassicae. Journal of Plant Growth Regulation, 28, $203-211$.

Kakkar, R.K. et al. (2000) Polyamines and plant morphogenesis. Biologia Plantarum, 43, 1-11.

Kandoth, P.K. et al. (2011) The soybean Rhg1 locus for resistance to the soybean cyst nematode Heterodera glycines regulates the expression of a large number of stress- and defense-related genes in degenerating feeding cells. Plant Physiology, 155, 1960-1975.

Karczmarek, A. et al. (2008) Expression of two functionally distinct plant endo-beta-1,4-glucanases is essential for the compatible interaction between potato cyst nematode and its hosts. Molecular Plant-Microbe Interactions, 21, 791-798.

Karczmarek, A. et al. (2004) Feeding cell development by cyst and root-knot nematodes involves a similar early, local and transient activation of a specific auxin-inducible promoter element. Molecular Plant Pathology, 5, 343-346.

Katan, J. (1996) Interactions of roots with soil-borne pathogens. In: Y. Waisel, A. Eshel, and U. Kafkafi (eds) Plant Roots: The Hidden Half. Marcel Dekker, New-York.

Katiyar-Agarwal, S. et al. (2007) A novel class of bacteria-induced small RNAs in Arabidopsis. Genes and Development, 21, 3123-3134.

Katiyar-Agarwal, S. et al. (2006) A pathogen-inducible endogenous siRNA in plant immunity. Proceedings of the National Academy of Sciences USA, 103, 18002-18007.

Kim, J.H. et al. (2003) The AtGRF family of putative transcription factors is involved in leaf and cotyledon growth in Arabidopsis. The Plant Journal, 36, 94-104.

Kim, J.H. and Kende, H. (2004) A transcriptional coactivator, AtGIF1, is involved in regulating leaf growth and morphology in Arabidopsis. Proceedings of the National Academy of Sciences USA, 101, 13374-13379.

Kim, J.H. and Lee, B.H. (2006) GROWTH-REGULATING FACTOR4 of Arabidopsis thaliana is required for development of leaves, cotyledons, and shoot apical meristem. Journal of Plant Biology, 49, 463-468.

Kirik, V. et al. (2001) CPR5 is involved in cell proliferation and cell death control and encodes a novel transmembrane protein. Current Biology, 11, 1891-1895.

Klink, V. et al. (2009) A gene expression analysis of syncytia laser microdissected from the roots of the Glycine max (soybean) genotype PI 548402 (Peking) undergoing a resistant reaction after infection by Heterodera glycines (soybean cyst nematode). Plant Molecular Biology, 71, 525-567.

Klink, V. et al. (2007a) Laser capture microdissection (LCM) and comparative microarray expression analysis of syncytial cells isolated from incompatible and compatible soybean (Glycine max) roots infected by the soybean cyst nematode (Heterodera glycines). Planta, 226, 1389-1409.

Klink, V. et al. (2007b) A time-course comparative microarray analysis of an incompatible and compatible response by Glycine max (soybean) to Heterodera glycines (soybean cyst nematode) infection. Planta, 226, 1423-1447.

Klink, V.P. et al. (2010) Syncytium gene expression in Glycine max [PI 88788] roots undergoing a resistant reaction to the parasitic nematode Heterodera glycines. Plant Physiology and Biochemistry, 48, 176-193.

Koltai, H. et al. (2001) Overlapping plant signal transduction pathways induced by a parasitic nematode and a rhizobial endosymbiont. Molecular Plant-Microbe Interactions, 14, 1168-1177.

Lambert, K.N. et al. (1999) Cloning and characterization of an esophageal-gland-specific chorismate mutase from the phytoparasitic nematode Meloidogyne javanica. Molecular Plant-Microbe Interactions, 12, 328-336.

Lee, C. et al. (2011) The novel cyst nematode effector protein 19C07 interacts with the Arabidopsis auxin influx transporter LAX3 to control feeding site development. Plant Physiology, 155, 866-880. 
Lelandais-Briere, C. et al. (2009) Genome-wide Medicago truncatula small RNA analysis revealed novel microRNAs and isoforms differentially regulated in roots and nodules. The Plant Cell, 21, 2780-2796.

Li, Y. et al. (2010) Identification of microRNAs involved in pathogen-associated molecular pattern-triggered plant innate immunity. Plant Physiology, 152, 2222-2231.

Lohar, D.P. et al. (2004) Cytokinins play opposite roles in lateral root formation, and nematode and rhizobial symbioses. The Plant Journal, 38, 203-214.

Lu, C. et al. (2005) Elucidation of the small RNA component of the transcriptome. Science, 309, 1567-1569.

Lu, S. et al. (2007) MicroRNAs in loblolly pine (Pinus taeda L.) and their association with fusiform rust gall development. The Plant Journal, 51, 1077-1098.

Lu, S.-W. et al. (2009) Structural and functional diversity of CLAVATA3/ESR (CLE)-Like genes from the potato cyst nematode Globodera rostochiensis. Molecular Plant-Microbe Interactions, 22, 1128-1142.

Ludwig-Müller, J. (2009) Plasmodiophora brassicae, the causal agent of clubroot disease: a review on molecular and biochemical events in pathogenesis. Journal of Plant Disease and Plant Protection, 106, 109-127.

Ludwig-Müller, J. et al. (2009) Metabolism and plant hormone action during clubroot disease. Journal of Plant Growth Regulation, 28, 229-244.

Ludwig-Müller, J. and Schuller, A. (2008) What can we learn from clubroots: alterations in host roots and hormone homeostasis caused by Plasmodiophora brassicae. European Journal of Plant Pathology, 121, 291-302.

Mazarei, M. et al. (2003) Expression of an Arabidopsis phosphoglycerate mutase homologue is localized to apical meristems, regulated by hormones, and induced by sedentary plant-parasitic nematodes. Plant Molecular Biology, 53, 513-530.

Mitchum, M. et al. (2004) The promoter of the Arabidopsis thaliana cel1 endo-1,4-beta glucanase gene is differentially expressed in plant feeding cells induced by root-knot and cyst nematodes. Molecular Plant Pathology, 5, 175-181.

Mitchum, M.G. et al. (2008) Diverse and conserved roles of CLE peptides. Current Opinion in Plant Biology, $11,75-81$.

Muller, R. et al. (2008) The receptor kinase CORYNE of Arabidopsis transmits the stem cell-limiting signal CLAVATA3 independently of CLAVATA1. Plant Cell, 20, 934-946.

Nahar, K. et al. (2011) The jasmonate pathway is a key player in systemically induced defense against root knot nematodes in rice. Plant Physiology, 157, 305-316.

Navarro, L. et al. (2006) A plant miRNA contributes to antibacterial resistance by repressing auxin signaling. Science, 312, 436-439.

Navarro, L. et al. (2008) Suppression of the microRNA pathway by bacterial effector proteins. Science, 321, 964-967.

Niebel, A. et al. (1996) Induction of cdc2a and cyc1 At expression in Arabidopsis thaliana during early phases of nematode-induced feeding cell formation. The Plant Journal, 10, 1037-1043.

Niebel, A. et al. (1993) Induction patterns of an extensin gene in tobacco upon nematode infection. The Plant Cell, 5, 1697-1710.

Oelkers, K. et al. (2008) Bioinformatic analysis of the CLE signaling peptide family. BMC Plant Biology, 8, 1.

Olmedo-Monfil, V. et al. (2010) Control of female gamete formation by a small RNA pathway in Arabidopsis. Nature 464, 628-632.

Opperman, C.H. et al. (2008) Sequence and genetic map of Meloidogyne hapla: a compact nematode genome for plant parasitism. Proceedings of the National Academy of Sciences USA, 105, 14802-14807.

Pandey, S.P. et al. (2008) Herbivory-induced changes in the small-RNA transcriptome and phytohormone signaling in Nicotiana attenuata. Proceedings of the National Academy of Sciences USA, 105, 4559-4564.

Patel, N. et al. (2010) A nematode effector protein similar to annexins in host plants. Journal of Experimental Botany, 61, $235-248$.

Portillo, M. et al. (2009) Isolation of RNA from laser-capture-microdissected giant cells at early differentiation stages suitable for differential transcriptome analysis. Molecular Plant Pathology, 10, 523-535.

Priya, D.B. et al. (2011) Transgenic tobacco plants constitutively expressing Arabidopsis NPR1 show enhanced resistance to root-knot nematode, Meloidogyne incognita. BMC Research Notes, 4, 231.

Puthoff, D.P. et al. (2007) GeneChip profiling of transcriptional responses to soybean cyst nematode, Heterodera glycines, colonization of soybean roots. Journal of Experimental Botany, 58, 3407-3418.

Puthoff, D.P. et al. (2003) Arabidopsis gene expression changes during cyst nematode parasitism revealed by statistical analyses of microarray expression profiles. The Plant Journal, 33, 911-921.

Pysh, L.D. et al. (1999) The GRAS gene family in Arabidopsis: sequence characterization and basic expression analysis of the SCARECROW-LIKE genes. The Plant Journal, 18, 111-119.

Qin, L. et al. (2004) Plant degradation: a nematode expansin acting on plants. Nature, 427, 30.

Ramsay, K. et al. (2006) Laser capture microdissection: a novel approach to microanalysis of plant-microbe interactions. Molecular Plant Pathology, 7, 429-435.

Ramsay, K. et al. (2004) Using laser capture microdissection to study gene expression in early stages of giant cells induced by root-knot nematodes. Molecular Plant Pathology, 5, 587-592.

Replogle, A. et al. (2011) Nematode CLE signaling in Arabidopsis requires CLAVATA2 and CORYNE. The Plant Journal, 65, 430-440. 
Richardson, L. and Price, N. (1984) Observations on the biology of Meloidogyne incognita and the Diageotropica tomato mutant. Revue de Nématologie, 7, 97-99.

Ron, M. et al. (2010) Proper regulation of a sperm-specific cis-nat-siRNA is essential for double fertilization in Arabidopsis. Genes and Development, 24, 1010-1021.

Sarkar, A.K. et al. (2007) Conserved factors regulate signalling in Arabidopsis thaliana shoot and root stem cell organizers. Nature, 446, 811-814.

Schaff, J.E. et al. (2007) Comprehensive transcriptome profiling in tomato reveals a role for glycosyltransferase in Mi-mediated nematode resistance. Plant Physiology, 144, 1079-1092.

Schwach, F. et al. (2009) Deciphering the diversity of small RNAs in plants: the long and short of it. Briefings in Functional Genomics and Proteomics, 8, 472-481.

Siemens, J. et al. (2006) Transcriptome analysis of Arabidopsis clubroots indicate a key role for cytokinins in disease development. Molecular Plant-Microbe Interactions, 19, 480-494.

Sobczak, M. et al. (2011) Cell wall modifications induced by nematodes. In: J. Jones, G. Gheysen, and C. Fenoll (eds) Genomics and Molecular Genetics of Plant-Nematode Interactions. Springer, New York, pp. 395-422.

Sobczak, M. and Golinowski, W. (2011) Cyst nematodes and syncytia. In: J.D. Jones, G. Gheysen and C. Fenoll (eds) Genomics and Molecular Genetics of Plant-Nematode Interactions, Springer, New York, pp. 61-82.

Strabala, T.J. et al. (2006) Gain-of-function phenotypes of many CLAVATA3/ESR genes, including four new family members, correlate with tandem variations in the conserved CLAVATA3/ESR domain. Plant Physiology, 140, 1331-1344.

Sunkar, R. et al. (2006) Posttranscriptional induction of two $\mathrm{Cu} / \mathrm{Zn}$ superoxide dismutase genes in Arabidopsis is mediated by downregulation of miR398 and important for oxidative stress tolerance. The Plant Cell, 18, 2051-2065.

Swarup, K. et al. (2008) The auxin influx carrier LAX3 promotes lateral root emergence. Nature Cell Biology, 10, 946-954.

Szakasits, D. et al. (2009) The transcriptome of syncytia induced by the cyst nematode Heterodera schachtii in Arabidopsis roots. The Plant Journal, 57, 771-784.

Trudgill, D.L. and Blok, V.C. (2001) Apomictic, polyphagous root-knot nematodes: exceptionally successful and damaging biotrophic root pathogens. Annual Review of Phytopathology, 39, 53-77.

Tucker, M.L. et al. (2007) Gene expression profiles for cell wall-modifying proteins associated with soybean cyst nematode infection, petiole abscission, root tips, flowers, apical buds, and leaves. Journal of Experimental Botany, 58, 3395-3406.

Tucker, M.L. et al. (2011) Gene expression profiling and shared promoter motif for cell wall-modifying proteins expressed in soybean cyst nematode-infected roots. Plant Physiology, 156, 319-329.

Van de Cappelle, E. et al. (2008) AtCDKA;1 silencing in Arabidopsis thaliana reduces reproduction of sedentary plant-parasitic nematodes. Plant Biotechnology Journal, 6, 749-757.

Van der Eycken, W. et al. (1996) A molecular study of root-knot nematode-induced feeding sites. The Plant Journal, 9, 45-54.

Vanholme, B. et al. (2009) Structural and functional investigation of a secreted chorismate mutase from the plant-parasitic nematode Heterodera schachtii in the context of related enzymes from diverse origins. Molecular Plant Pathology, 10, $189-200$.

Vaucheret, H. (2006) Post-transcriptional small RNA pathways in plants: mechanisms and regulations. Genes and Development, 20, 759-771.

Vercauteren, I. et al. (2002) An Arabidopsis thaliana pectin acetylesterase gene is upregulated in nematode feeding sites induced by root-knot and cyst nematodes. Molecular Plant-Microbe Interactions, 15, 404-407.

Waetzig, G.H. et al. (1999) Localization of hydrogen peroxide during the defence response of Arabidopsis thaliana against the plant-parasitic nematode Heterodera glycines. Nematology, 1, 681-686.

Wang, J. et al. (2010) Dual roles for the variable domain in protein trafficking and host-specific recognition of Heterodera glycines CLE effector proteins. New Phytologist, 187, 1003-1017.

Wang, J. et al. (2011) Identification of potential host plant mimics of CLAVATA3/ESR (CLE)-like peptides from the plant-parasitic nematode Heterodera schachtii. Molecular Plant Pathology, 12, 177-186.

Wang, X. et al. (2001) Signal peptide-selection of cDNA cloned directly from the esophageal gland cells of the soybean cyst nematode Heterodera glycines. Molecular Plant-Microbe Interactions, 14, 536-544.

Wang, X. et al. (2005) A parasitism gene from a plant-parasitic nematode with function similar to CLAVATA3/ESR (CLE) of Arabidopsis thaliana. Molecular Plant Pathology, 6, 187-191.

Wang, X. et al. (2007) The tobacco Cel7 gene promoter is auxin-responsive and locally induced in nematode feeding sites of heterologous plants. Molecular Plant Pathology, 8, 423-436.

Wang, Z. et al. (2003) Differential display analysis of gene expression in the cytoplasm of giant cells induced in tomato roots by Meloidogyne javanica. Molecular Plant Pathology, 4, 361-371.

Wasson, A.P. et al. (2009) Differing requirements for flavonoids during the formation of lateral roots, nodules and root knot nematode galls in Medicago truncatula. New Phytologist, 183, 167-179.

Whitford, R. et al. (2008) Plant CLE peptides from two distinct functional classes synergistically induce division of vascular cells. Proceedings of the National Academy of Sciences USA, 105, 18625-18630. 
Wieczorek, K. et al. (2006) Expansins are involved in the formation of nematode-induced syncytia in roots of Arabidopsis thaliana. The Plant Journal, 48, 98-112.

Wieczorek, K. and Grundler, F.M.W. (2006) Expanding nematode-induced syncytia: the role of expansins. Plant Signaling and Behavior, 1, 223-224.

Wieczorek, K. et al. (2008) Arabidopsis endo-1,4-beta-glucanases are involved in the formation of root syncytia induced by Heterodera schachtii. The Plant Journal, 53, 336-351.

Wildermuth, M.C. (2010) Modulation of host nuclear ploidy: a common plant biotroph mechanism. Current Opinion in Plant Biology, 13, 449-458.

Wubben, M. J., 2nd et al. (2001) Susceptibility to the sugar beet cyst nematode is modulated by ethylene signal transduction in Arabidopsis thaliana. Molecular Plant-Microbe Interactions, 14, 1206-1212.

Xie, Q. et al. (2000) Arabidopsis NAC1 transduces auxin signal downstream of TIR1 to promote lateral root development. Genes and Development, 14, 3024-3036. 